\title{
Natriuretic Response to Renal Medullary Endothelin B Receptor Activation Is Impaired in Dahl-Salt Sensitive Rats on a High-Fat Diet
}

\author{
W. KITTIKULSUTH ${ }^{1}$, K. A. HYNDMAN ${ }^{1}$, J. S. POLLOCK ${ }^{1}$, D. M. POLLOCK ${ }^{1}$ \\ ${ }^{1}$ Section of Cardio-Renal Physiology and Medicine, Division of Nephrology, Department of \\ Medicine, University of Alabama at Birmingham, Birmingham, AL, USA
}

Received January 13, 2018

Accepted March 29, 2018

\section{Summary}

Renal medullary endothelin $B$ receptors $\left(E T_{B}\right)$ mediate sodium excretion and blood pressure (BP) control. Several animal models of hypertension have impaired renal medullary $\mathrm{ET}_{\mathrm{B}}$ function. We found that 4-week high-caloric diet elevated systolic BP in Dahl salt-sensitive (Dahl S) rats $(126 \pm 2$ vs. $143 \pm 3 \mathrm{~mm} \mathrm{Hg}, \mathrm{p}<0.05)$. We hypothesized that renal medullary $\mathrm{ET}_{\mathrm{B}}$ function is dysfunctional in DS rats fed a high-caloric diet. We compared the diuretic and natriuretic response to intramedullary infusion of $\mathrm{ET}_{\mathrm{B}}$ agonist sarafotoxin $6 \mathrm{c}(\mathrm{S} 6 \mathrm{c})$ in DS rats fed either a normal or high-caloric diet for 4 weeks. Urine was collected during intramedullary infusion of saline for baseline collection followed by intramedullary infusion of either saline or S6c. We first examined the $\mathrm{ET}_{\mathrm{B}}$ function in DS rats fed a normal diet. S6C increased urine flow $(2.7 \pm 0.3 \mu \mathrm{l} / \mathrm{min}$ during baseline vs. $5.1 \pm 0.6 \mu \mathrm{l} / \mathrm{min}$ after S6c; $\mathrm{p}<0.05 ; \mathrm{n}=5)$ and sodium excretion ( $0.28 \pm 0.05$ vs. $0.81 \pm 0.17 \mu \mathrm{mol} / \mathrm{min} ; \mathrm{p}<0.05)$, suggesting that $D S$ rats have renal medullary $\mathrm{ET}_{\mathrm{B}}$ function. However, $\mathrm{DS}$ rats fed a high-caloric diet displayed a significant increase in urine flow $(2.7 \pm 0.4$ vs. $4.2 \pm 0.4 \mu \mathrm{l} / \mathrm{min}$, baseline vs. S6c infusion, respectively; $p<0.05$, $\mathrm{n}=6)$, but no significant change in sodium excretion in response to S6c $(0.32 \pm 0.06$ vs. $0.45 \pm 0.10 \mu \mathrm{mol} / \mathrm{min})$. These data demonstrate that renal medullary $\mathrm{ET}_{\mathrm{B}}$ function is impaired in DS rats fed a high-caloric diet, which may be contributed to the elevation of blood pressure during high-caloric feeding in this model.

\section{Key words}

High fat diet $\bullet$ Obesity $\bullet \mathrm{ET}_{\mathrm{B}}$ receptor $\bullet$ Sarafotoxin $6 \mathrm{c} \bullet$ Renal medulla $\bullet$ Natriuresis

\section{Corresponding author}

D. M. Pollock, Section of Cardio-Renal Physiology and Medicine, Division of Nephrology, Department of Medicine, University of
Alabama at Birmingham, $72020^{\text {th }}$ Street S, Kaul 802B, Birmingham, AL 35233, USA. Fax: (205) 975-7520. E-mail: davidpollock@uabmc.edu

\section{Introduction}

Renal control of sodium excretion involves a wide range of factors that control tubular reabsorption of filtered sodium. Our lab and others have developed a long line of evidence that endothelin (ET) is important for blood pressure control by promoting the kidney's ability to excrete sodium in response to high salt intake (Kohan et al. 2011). These actions are primarily via ET-1 stimulating the $\mathrm{ET}_{\mathrm{B}}$ receptor in the collecting duct of the kidney. The inability of renal $\mathrm{ET}_{\mathrm{B}}$ receptors to inhibit sodium reabsorption contributes to salt-sensitive hypertension (Kohan 2013). Consistent with this idea, Speed et al. (2011) demonstrated that the ET-1/ET natriuretic pathway is impaired in the Dahl salt-sensitive (Dahl S) rat.

Obesity is a major risk factor for the development of cardiovascular disease that is closely associated with hypertension (Hall et al. 2015). While it is generally agreed upon that the root cause of obesity is due to taking in more calories than are being used, this can occur due to a number of genetic and environmental stressors. They include sedentary lifestyle, impaired leptin production or signaling, and others such as high salt intake. Of note, high salt intake is a lifestyle factor that is a powerful stimulus for ET-1 production by the kidney, but also in extra-renal tissues including skin and vasculature (Speed et al. 2015). However, less studied is the observation that high fat diets can increase renal 
tissue ET-1 content (Barton et al. 2000).

Thus, the present study was designed to test the hypothesis that a high fat diet is associated with an impairment of $\mathrm{ET}_{\mathrm{B}}$ receptor dependent natriuresis in a model of salt-sensitivity. Our hypothesis predicts that the natriuretic response to an $\mathrm{ET}_{\mathrm{B}}$ receptor agonist infused into the renal medulla of anesthetized Dahl S rats will be reduced in rats on a high fat compared to a normal fat diet.

\section{Methods}

\section{Animals}

Studies used male Dahl S rats between 8 and 10 weeks old purchased from Harlan Laboratories (Indianapolis, IN, USA). All rats were allowed to acclimate to their cages for at least one week prior to experimentation and continuously housed at a constant temperature and humidity and a 12:12-h light-dark cycle. All experiments and procedures were approved and monitored by the Augusta University Institutional Animal Care and Use Committee in accordance with the NIH Guide for the Care and Use of Laboratory Animals. Rats were placed on a normal fat diet $(16.6 \%$ kcal fat, Harlan Teklad, Madison, WI, USA) or high fat diet $(58.7 \% \mathrm{kcal}$ fat, Harlan Teklad, Madison, WI, USA) for a period of 4 weeks. Both diets have what is typically considered normal salt content $(0.4 \% \mathrm{NaCl})$.

\section{Metabolic and renal function}

Each week while on normal or high fat diet, rats were placed in metabolic cages to assess food and water intake and urine collection. Each week, rats were allowed a $24 \mathrm{~h}$ acclimation to the metabolic cage followed by a 24-h urine collection. Systolic arterial pressure was also measured by tail cuff plethysmography as previously described (D'Angelo et al. 2005).

\section{Analysis of $E T_{B^{-}}$-dependent natriuresis}

At the end of 4 weeks on each diet, rats were anesthetized with inactin $(100 \mathrm{mg} / \mathrm{kg}$ i.p.) and placed on a temperature controlled surgical table and surgically prepared as previously described (Nakano et al. 2008, Kittikulsuth et al. 2012). A catheter was placed in the jugular vein for infusion of saline $(0.9 \% \mathrm{NaCl})$ containing $4 \% \mathrm{BSA}$ at $30 \mu \mathrm{l} / \mathrm{min}$ during surgery and reduced to $15 \mu \mathrm{l} / \mathrm{min}$ after surgery to maintain euvolemia. A similar catheter was placed in the femoral artery to monitor arterial pressure. A midline incision was used to access the left kidney and insert a stretched PE-10 catheter $5 \mathrm{~mm}$ into the kidney from the lateral side to reach the inner/outer medullary junction. Saline was infused into the catheter at a rate of $0.5 \mathrm{ml} / \mathrm{h}$ and the position of the catheter was verified at the end of each experiment by dissecting the kidney. A ureteral catheter was used to collect urine from each kidney. Animals were allowed a 60-min equilibration period followed by a baseline urine collection of $40 \mathrm{~min}$. The intramedullary infusion was then changed to saline containing sarafotoxin 6c (S6c, American Peptide Co., Sunnyvale, CA, USA) at $0.45 \mu \mathrm{g} / \mathrm{kg} / \mathrm{h}$ for an additional $80 \mathrm{~min}$. Separate groups of rats were maintained on saline $(0.9 \%$ $\mathrm{NaCl}$ ) infusion into the renal medulla throughout the protocol to serve as time controls. Urine collected during the final $20 \mathrm{~min}$ of the baseline and experimental periods were used for analysis.

\section{Receptor-binding assay to endothelin-1 and endothelin-3}

In a separate set of identically treated rats (normal and high fat diets), rats were anesthetized with $\mathrm{Na}$ pentobarbital $(65 \mathrm{mg} / \mathrm{kg}$ i.p.) and blood drawn from the abdominal aorta followed immediately by removing the kidney. The inner medulla was then removed before being snap frozen for receptor-binding analysis. In brief, tissue was homogenized and plasma membrane fractions prepared for binding studies as previously described (Kittikulsuth et al. 2011). Plasma membrane and wheat germ agglutinin polyvinyltoluene beads (PerkinElmer, Boston, MA, USA) were added into each well and incubated for $3 \mathrm{~h}$. Then, $\left[{ }^{125} \mathrm{I}\right]-\mathrm{ET}-1$ (PerkinElmer, Boston, MA, USA) at the final concentration of $0.01-1.0 \mathrm{nM}$ or $\left[{ }^{125} \mathrm{I}\right]-\mathrm{ET}-3$ (PerkinElmer, Boston, MA, USA) at the final concentration of $0.06-1.0 \mathrm{nM}$ was added and incubated for $18 \mathrm{~h}$. Total binding of $\left[{ }^{125} \mathrm{I}\right]$-ET-1 or $\left[{ }^{125} \mathrm{I}\right]$-ET-3 was determined using 0.3 or $1 \mu \mathrm{g}$ plasma membrane protein, respectively. Nonspecific binding was determined in the presence of $10 \mu \mathrm{M}$ unlabeled ET-1 or ET-3 ligand (American Peptide, Inc., Sunnyvale, CA, USA). All measurements were performed in duplicate.

Assays

Urinary sodium concentration was measured by atomic absorption. Urinary ET-1 excretion was measured by radioimmunoassay via the manufacturer's protocol (Peninsula Laboratories, San Carlos, CA, USA).

\section{Statistical analysis}

Urine flow rate, urinary sodium excretion and 
mean arterial pressure in response to intramedullary infusion of saline or S6c were analyzed by two-way repeated-measures ANOVA followed by Bonferroni post hoc tests among rats receiving a normal or high fat diet. Similarly, metabolic parameters were analyzed by
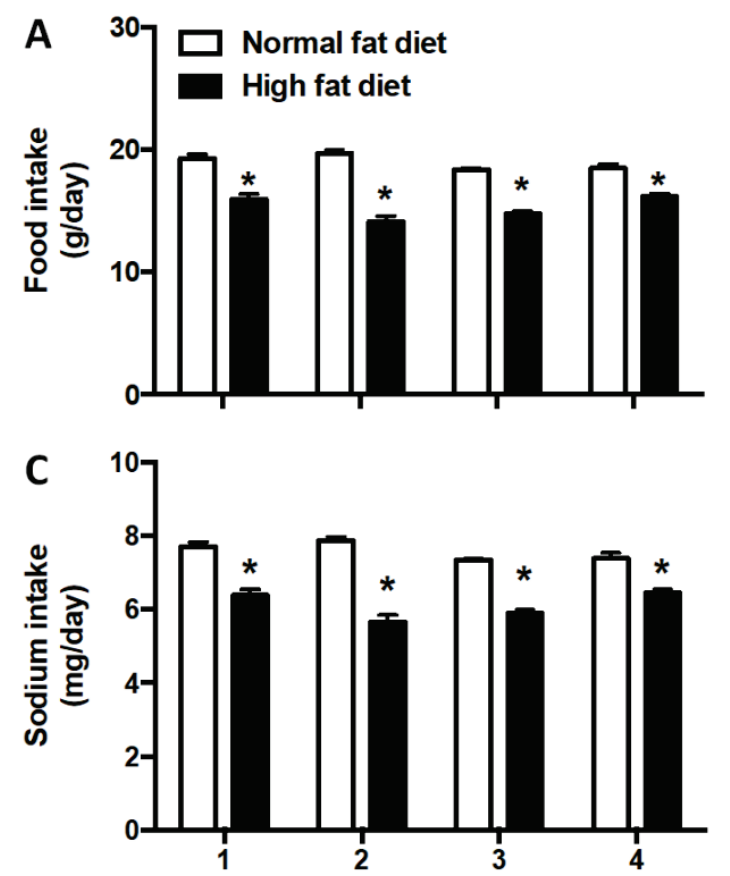

two-way ANOVA for repeated measures followed by Bonferroni post hoc tests. Binding data were analyzed using Student's t-test (two-tailed). Results are expressed as mean \pm SE with $p<0.05$ being considered statistically significant.
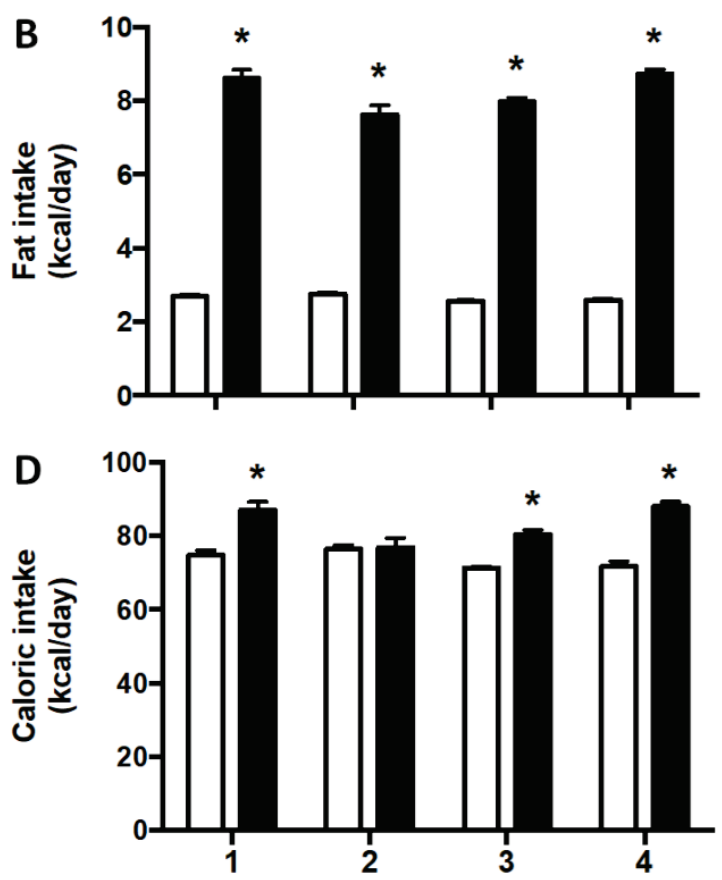

Fig. 1. Intake of food (A), fat (B), sodium (C), and calories (D) in Dahl S rats given a normal $(n=8)$ or high fat $(n=5)$ diet. * denotes $\mathrm{p}<0.05$ vs. normal fat group at each week.

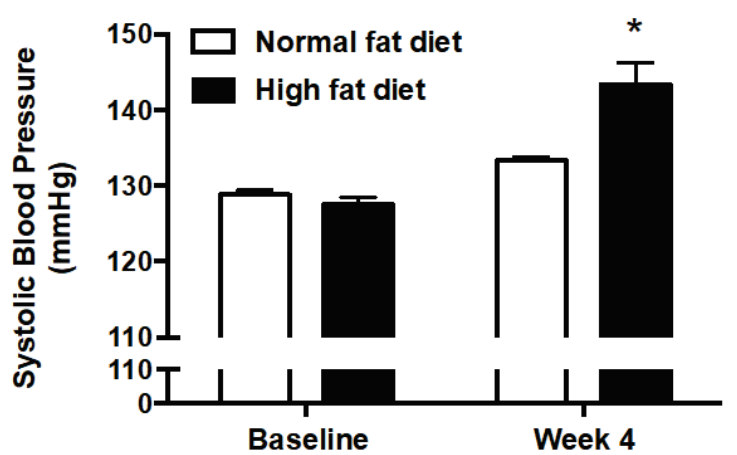

Fig. 2. Systolic blood pressure (tail cuff) measured in Dahl $S$ rats before and after 4 weeks of a normal $(n=6)$ or high fat $(n=5)$ diet. * denotes $\mathrm{p}<0.05$ vs. normal fat group.

\section{Results}

\section{4-h measurements}

Figure 1 displays food and related intake data in Dahl S rats from 1 to 4 weeks of normal or high fat feeding. Rats eating the high fat diet ate less food than those eating the normal fat diet, although by design, the amount of high fat ingested was much higher (Fig. 1B). However, caloric intake was significantly higher in the group eating the high fat diet due to the greater energy content in the high fat diet. Thus, since the $\mathrm{NaCl}$ content was identical in both groups, the total sodium intake was roughly $20 \%$ lower in rats eating the high fat diet (Fig. 1C). As previously reported, we observed that the high fat diet produced a significant increase in systolic blood pressure in the Dahl S rat (Fig. 2). While urinary ET-1 was lower in rats on a high fat diet $(3.4 \pm 0.5 \mathrm{ng} /$ day, $\mathrm{n}=5)$ compared to normal fat $(4.7 \pm 0.5 \mathrm{ng} /$ day, $\mathrm{n}=6)$, this difference did not reach statistical significance.

\section{Intramedullary $E T_{B}$ receptor function}

As previously reported, intramedullary infusion of the $\mathrm{ET}_{\mathrm{B}}$ receptor agonist, $\mathrm{S} 6 \mathrm{c}$, in anesthetized rats produced a significant increase in urine flow rate (Fig. 3A) and urinary sodium excretion (Fig. 3C) in rats on a normal fat diet. In contrast, intramedullary infusion of S6c did not significantly increase urine flow rate (Fig. 3B) or urinary sodium excretion (Fig. 3D) in rats on a high fat diet. Mean arterial pressure remained unchanged during intramedullary infusion of saline or S6c on either diet (Figs 4A and 4B). 

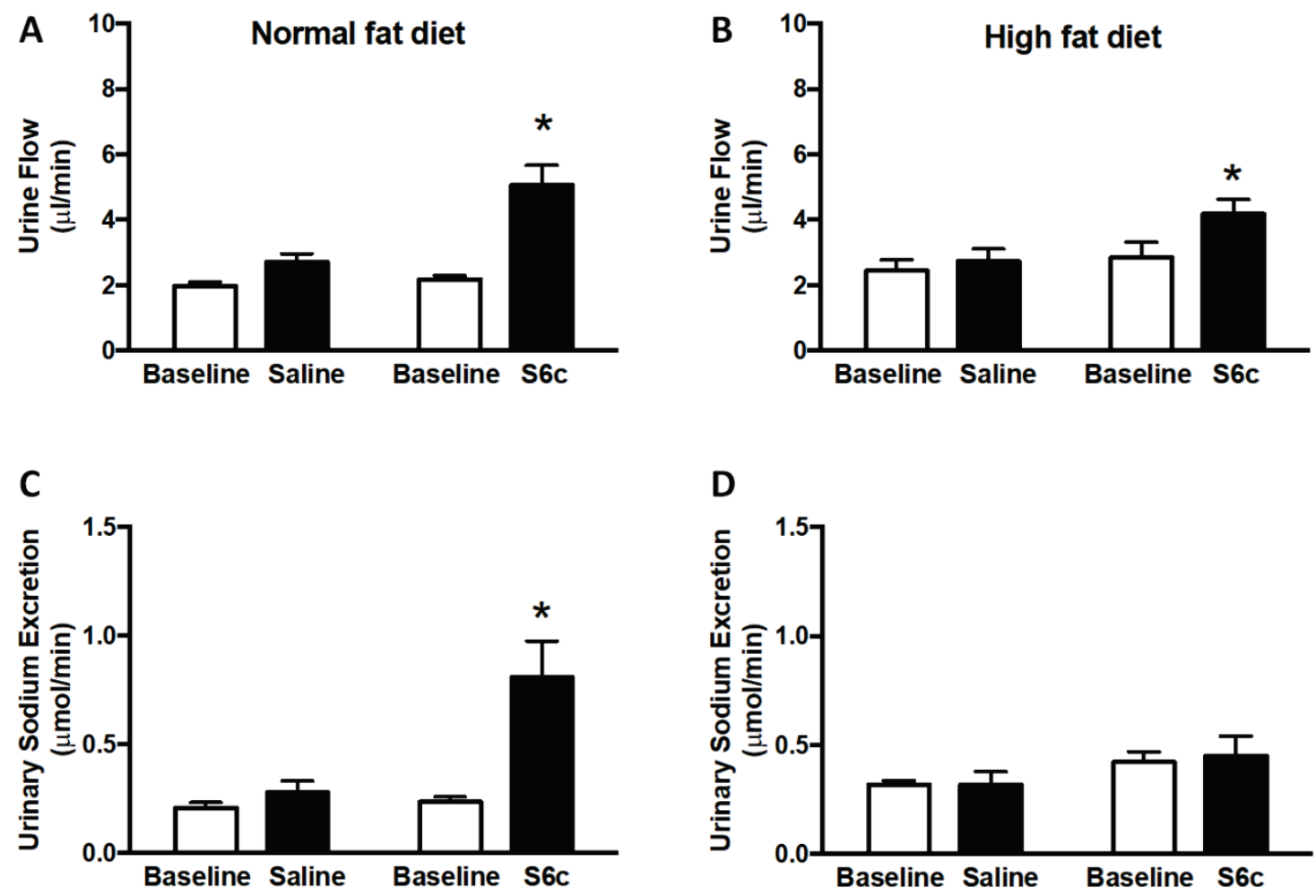

Fig. 3. Urine flow rate $(\mathbf{A}, \mathbf{B})$ and sodium excretion (C, D) in anesthetized Dahl $\mathrm{S}$ rats during baseline and intramedullary infusion of either saline or sarafotoxin $6 \mathrm{c}(\mathrm{S} 6 \mathrm{C})$. Separate groups of animals were maintained for 4 weeks on a normal $(A, C ; n=6)$ or high fat $(B, D ; n=5)$ diet. * denotes $p<0.05$ vs. corresponding baseline value.
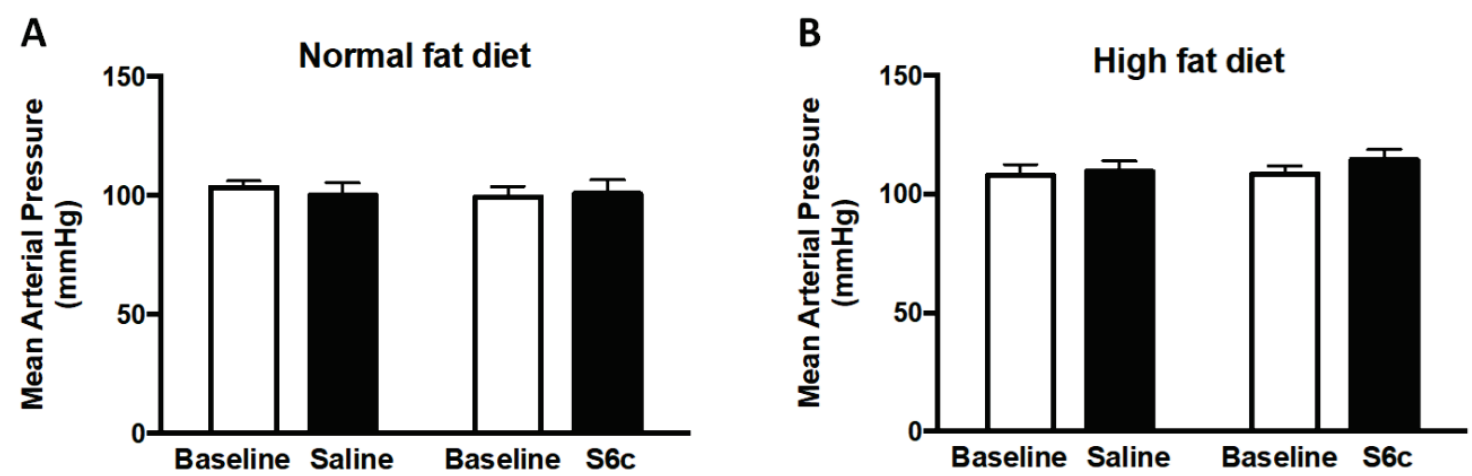

Fig. 4. Mean arterial pressure in anesthetized Dahl $S$ rats during baseline and intramedullary infusion of either saline or sarafotoxin $6 \mathrm{c}$ (S6c). Separate groups of animals were maintained for 4 weeks on a normal $(\mathbf{A} ; n=6)$ or high fat $(\mathbf{B} ; n=5)$ diet. There was no statistically significant effect of S6c and baseline or diet groups.

\section{$E T_{A}$ and $E T_{B}$ receptor binding}

As in previous studies, we took advantage of the differential binding of ET-1 and ET-3 peptides to discern maximum binding to $\mathrm{ET}_{\mathrm{A}}$ and $\mathrm{ET}_{\mathrm{B}}$ receptors. Using membrane preparations from inner medullary tissue, Scatchard analysis was used to determine maximum binding (Bmax) values of $\left[{ }^{125} \mathrm{I}\right]$-ET-1 binding sites that represent total $\mathrm{ET}_{\mathrm{A}}$ and $\mathrm{ET}_{\mathrm{B}}$ receptor binding, and Bmax values of $\left[{ }^{125} \mathrm{I}\right]$-ET-3 binding sites represent specific $\mathrm{ET}_{\mathrm{B}}$ receptor binding as previously described. The difference between Bmax values of $\left[{ }^{125} \mathrm{I}\right]$-ET-1 and $\left[{ }^{125} \mathrm{I}\right]$-ET-3 binding was used to determine $\mathrm{ET}_{\mathrm{A}}$ receptor binding, which was not significantly different between tissues taken from rats on a normal and high fat diet (Fig. 5A). Bmax for $\mathrm{ET}_{\mathrm{B}}$ receptor binding in renal inner medullary tissue from rats on a high fat diet was significantly lower than values obtained from tissue taken from rats on a normal fat diet (Fig. 5B). Dissociation constants $\left(\mathrm{K}_{\mathrm{d}}\right)$ for $\left[{ }^{125} \mathrm{I}\right]-\mathrm{ET}-1$ were comparable between inner medullary preparations from rats on a normal or high fat diet $(0.063 \pm 0.009$ and $0.062 \pm 0.011$, respectively). In contrast, the $\mathrm{K}_{\mathrm{d}}$ for $\left[{ }^{125} \mathrm{I}\right]$-ET-3 binding was significantly lower in the high fat vs. normal fat groups $(0.065 \pm 0.002 \mathrm{nM}$ and $0.114 \pm 0.007 \mathrm{nM}$, respectively). 

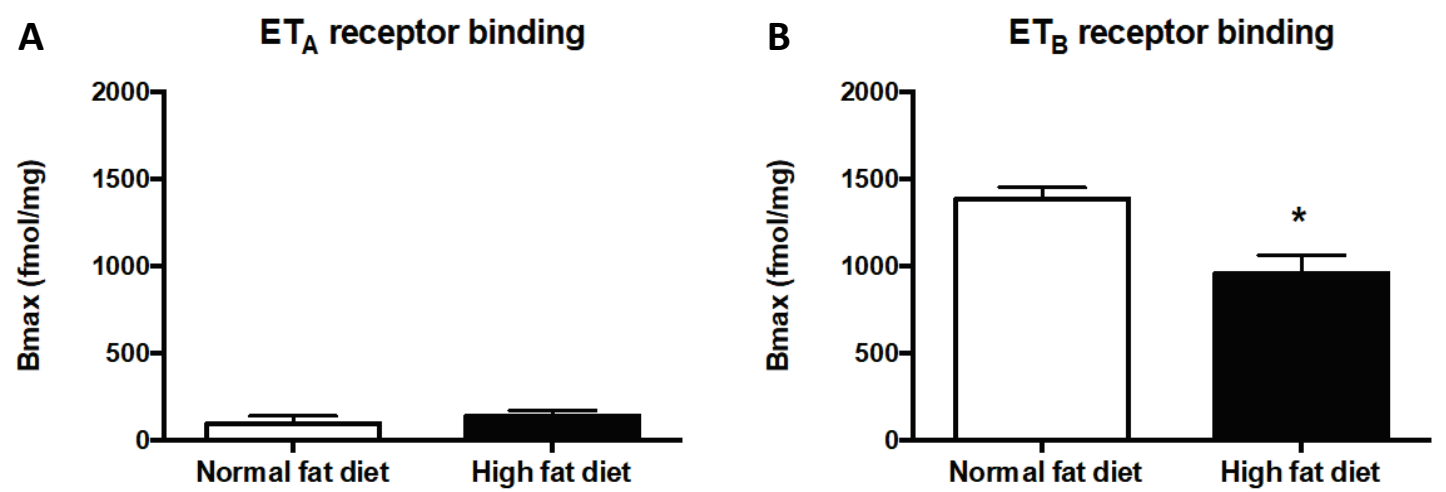

Fig. 5. Maximum binding for $E T_{A}$ receptors (A; total $E T-1$ binding minus $E T-3$ binding) and $E T_{B}$ receptors (B; $E T-3$ binding) in Dahl $S$ rats on normal or high fat diets $(n=3$ each; $p<0.05)$.

\section{Discussion}

There is growing evidence that high salt diets contribute to obesity-dependent hypertension (Hall et al. 2015). However, the possible intrarenal mechanisms that could account for this form of salt-sensitivity are not known. The current study demonstrates that one of the more influential natriuretic pathways, the $\mathrm{ET}_{\mathrm{B}}$ receptor, loses its ability to produce a natriuresis in a susceptible strain of rat when placed on a high fat diet. Physiologically, the kidney plays a key role in blood pressure regulation through control of salt and water balance. Loss of the $\mathrm{ET}_{\mathrm{B}}$ receptor, whether through genetic deletion or pharmacological blockade, results in hypertension that is very sensitive to dietary salt intake (Kohan et al. 2011). More specifically, these receptors are in greatest abundance within the renal medulla and in particular the inner medullary collecting duct. The current findings support the hypothesis that the contribution of high fat diets towards hypertension could be relate to a loss of $\mathrm{ET}_{\mathrm{B}}$ receptor function in the renal medulla. Of course, further studies are needed to provide a more definitive cause and effect, but these studies show a clear, non-salt-dependent effect of dietary changes that can impact this important natriuretic system.

We know from the work of Speed and colleagues that the Dahl S rat already has reduced renal medullary ET-1 and $\mathrm{ET}_{\mathrm{B}}$ receptor activity since salt-induced hypertension in this model was attenuated by chronic intramedullary infusion of ET-1 (Speed et al. 2011). The current study provides rationale for further investigation into the potential role for $\mathrm{ET}_{\mathrm{B}}$ receptor dysfunction in obesity-dependent hypertension. However, the mechanism for how $\mathrm{ET}_{\mathrm{B}}$ receptor function is lost in the Dahl S rat is not known. Recent findings from our group demonstrate that both exogenous and endogenous angiotensin II causes a loss of $\mathrm{ET}_{\mathrm{B}}$-dependent natriuresis and a down-regulation of inner medullary $\mathrm{ET}_{\mathrm{B}}$ receptor expression (Kittikulsuth et al. 2012, Kittikulsuth et al. 2013). Thus, the renin-angiotensin system could account for this loss of function since Spradley et al. (2013) have shown that high fat diet increases plasma renin activity in the Dahl S rat. Our study was powered to assess the natriuretic response to S6c, however, further studies will be need to determine whether adiposity impairs renal ET-1 production.

High fat feeding is often used as a surrogate for obesity in animal models. While rodents often do not get obese, the Dahl S model on a high fat diet has an obese phenotype (Spradley et al. 2013). Our group has previously reported that 4 weeks of high fat diet results in a significant increase in body weight and fat distribution as well as many other factors associate with obesity such as elevate triglycerides and free fatty acids (Spradley et al. 2013). This study also used telemetry to show that this diet regimen causes hypertension in the Dahl S model as we confirmed by tail cuff even though we did not see this blood pressure difference when the animals were anesthetized.

Because the high fat chow has a greater caloric content, we observed that Dahl S rats consuming a high fat diet actually consumed less food, although they consumed more calories. Since the high fat diet has identical sodium content compared to the matched normal fat diet, the animals actually ate about $20 \%$ less sodium. Therefore, we cannot rule out the possibility that even this small reduction in sodium intake could reduce $\mathrm{ET}_{\mathrm{B}}$ receptor expression/function. This will need to be examined in future studies. Spradley et al. (2013) also showed that the high fat diet exacerbates renal inflammation in the Dahl $\mathrm{S}$ rat, which is a known stimulus for excess ET-1 production and tubular 
dysfunction. Again, future studies will need to explore whether these inflammatory mechanisms contribute to $\mathrm{ET}_{\mathrm{B}}$ receptor dysfunction.

\section{Conflict of Interest}

There is no conflict of interest.

\section{Acknowledgements}

The National Institutes of Health (HL69999 and HL136267 to DMP and JSP), NIDDK (K01DK105038 to $\mathrm{KAH}$ ), an American Heart Association Strategically Focused Research Network Grant on Hypertension (JSP), and AHA pre-doctoral fellowship (W. Kittikulsuth) supported this work.

\section{References}

BARTON M, CARMONA R, MORAWIETZ H, D'USCIO LV, GOETTSCH W, HILLEN H, HAUDENSCHILD CC, KRIEGER JE, MUNTER K, LATTMANN T, LUSCHER TF, SHAW S: Obesity is associated with tissuespecific activation of renal angiotensin-converting enzyme in vivo: evidence for a regulatory role of endothelin. Hypertension 35: 329-336, 2000.

D'ANGELO G, ELMARAKBY AA, POLLOCK DM, STEPP DW: Fructose feeding increases insulin resistance but not blood pressure in Sprague-Dawley rats. Hypertension 46: 806-811, 2005.

HALL JE, Do CARMO JM, DA SILVA AA, WANG Z, HALL ME: Obesity-induced hypertension: interaction of neurohumoral and renal mechanisms. Circ Res 116: 991-1006, 2015.

KITTIKULSUTH W, POLLOCK JS, POLLOCK DM: Sex differences in renal medullary endothelin receptor function in angiotensin II hypertensive rats. Hypertension 58: 212-218, 2011.

KITTIKULSUTH W, POLLOCK JS, POLLOCK DM: Loss of renal medullary endothelin B receptor function during salt deprivation is regulated by angiotensin II. Am J Physiol Renal Physiol 303: F659-F666, 2012.

KITTIKULSUTH W, LOONEY SW, POLLOCK DM: Endothelin $\mathrm{ET}_{\mathrm{B}}$ receptors contribute to sex differences in blood pressure elevation in angiotensin II hypertensive rats on a high-salt diet. Clin Exp Pharmacol Physiol 40: 362-370, 2013.

KOHAN DE: Role of collecting duct endothelin in control of renal function and blood pressure. Am J Physiol Regul Integr Comp Physiol 305: R659-R668, 2013.

KOHAN DE, INSCHO EW, WESSON D, POLLOCK DM: Physiology of endothelin and the kidney. Compr Physiol 1: 883-919, 2011.

NAKANO D, POLLOCK JS, POLLOCK DM: Renal medullary $\mathrm{ET}_{\mathrm{B}}$ receptors produce diuresis and natriuresis via NOS1. Am J Physiol Renal Physiol 294: F1205-F1211, 2008.

SPEED JS, LAMARCA B, BERRY H, COCKRELL K, GEORGE EM, GRANGER JP: Renal medullary endothelin-1 is decreased in Dahl salt-sensitive rats. Am J Physiol Regul Integr Comp Physiol 301: R519-R523, 2011.

SPEED JS, HEIMLICH JB, HYNDMAN KA, FOX BM, PATEL V, YANAGISAWA M, POLLOCK JS, TITZE JM, POLLOCK DM: Endothelin-1 as a master regulator of whole-body $\mathrm{Na}^{+}$homeostasis. FASEB $J$ 29: 4937-4944, 2015.

SPRADLEY FT, DE MIGUEL C, HOBBS J, POLLOCK DM, POLLOCK JS: Mycophenolate mofetil prevents high-fat diet-induced hypertension and renal glomerular injury in Dahl SS rats. Physiol Rep 1: e00137, 2013. 